(2) Open Access Full Text Article

\title{
Comparison of clear lens extraction and collamer lens implantation in high myopia
}

\author{
Ahmed M Emarah \\ Mostafa A El-Helw \\ Hazem MYassin \\ Cairo University, Cairo, Egypt
}

This article was published in the following Dove Press journal:

Clinical Ophthalmology

7 May 2010

Number of times this article has been viewed

Aim: To compare the outcomes of clear lens extraction and collamer lens implantation in high myopia.

Patients and methods: Myopic patients younger than 40 years old with more than 12 diopters of myopia or who were not fit for laser-assisted in situ keratomileusis were included. Group 1 comprised patients undergoing clear lens extraction and Group 2 patients received the Visian implantable collamer lens. Outcome and complications were evaluated.

Results: Postoperative best corrected visual acuity was $-0.61 \pm 0.18$ in Group 1 and $0.79 \pm 0.16$ in Group 2. In Group 1, 71.4\% achieved a postoperative uncorrected visual acuity better than the preoperative best corrected visual acuity, while only $51.8 \%$ patients achieved this in Group 2 . Intraocular pressure decreased by $12.55 \%$ in Group 1 , and increased by $15.11 \%$ in Group 2 . Corneal endothelial cell density decreased by $4.47 \%$ in Group 1 and decreased by $5.67 \%$ in Group 2 . Posterior capsule opacification occurred in Group 1. In Group 2, lens opacification occurred in $11.11 \%$, significant pigment dispersion in $3.7 \%$, and pupillary block glaucoma in $3.7 \%$.

Conclusion: Clear lens extraction presents less of a financial load up front, and less likelihood of the need for a secondary intervention in the future. Clear lens extraction is a more viable solution in developing countries with limited financial resources.

Keywords: clear lens extraction, implantable collamer lens, myopia

\section{Introduction}

The personal and socioeconomic impact of myopia is well documented. ${ }^{1,2}$ The poor visual quality of spectacle-corrected high emmetropia with inherent optical aberrations, secondary psychologic problems, and frequent intolerance to contact lenses, justify the search for new technology in the correction of high ametropia. ${ }^{3}$

Surgical correction of high ametropia is a controversial issue..$^{4-7}$ Despite the widespread acceptance of laser-assisted in situ keratomileusis (LASIK) within the ophthalmic community, this moderately invasive technique that directly affects the clear, central, optical zone is associated with a sizeable number of potential intraoperative and postoperative complications, the incidence of which has been found to increase with higher refractive errors. ${ }^{8}$ To this contributes the fact that the use of Excimer laser corneal ablation has some limitations concerning the amount of corneal tissue that can be removed, ${ }^{9}$ the predictability and stability of photorefractive techniques decreases with the amount of attempted correction, and corneal ectasia might occur as a result of large ablation depths. ${ }^{10}$ Additionally, altering the shape of the cornea in attempted high photorefractive corrections may result in poor quality of vision. ${ }^{11}$

\footnotetext{
Correspondence: Mostafa El-Helw Cairo University, 52 Manyal Street, Manyal, Cairo, I I45I, Egypt

Tel +l I 20I 01228920

Fax + II 20I 27474858

Email helw@yahoo.com
} 
Fukala is considered the pioneer of clear lens extraction (CLE) for the correction of myopic eyes. ${ }^{12}$ Extracting the clear lens is one procedure that has been used to treat high myopia for a long time. ${ }^{13,14}$ The primary concern with this procedure is its association with an increased risk of retinal complications..$^{14,15}$ CLE is an invasive procedure that can result in severe visual loss. Albeit rare, the primary risk is an increased potential for retinal detachment. Other potential complications include cystoids, macular edema, and endophthalmitis. Despite these severe complications, advances in surgical techniques have led surgeons to reconsider this option and to weigh the risks against the benefits of the procedure. ${ }^{16}$

Phakic intraocular implants can correct high myopia and hyperopia, with the advantages of reversibility, stability of the correction, and to a great extent, preservation of accommodation. ${ }^{8,17-26} \mathrm{An}$ increasing number of procedures are being performed because of the expectation of a superior quality of vision obtained with phakic intraocular lens (IOL) implantation with respect to keratorefractive surgery for the correction of high ametropias. ${ }^{27-30}$ However, induced cataract and glaucoma are at the heart of most concerns regarding these intraocular surgical procedures, especially for posterior chamber phakic IOLs. ${ }^{31-39}$ This study was conducted with the aim of comparing CLE and the implantable collamer lens (ICL) in correction of high myopia in the patients younger than 45 years.

\section{Patients and methods}

\section{Patient selection and preparation}

This was a prospective, nonrandomized interventional study carried out on 55 eyes in 31 patients seeking treatment of myopia. The research followed the tenets of the Declaration of Helsinki, and informed consent was obtained from patients, to whom all details of the procedure were explained, with emphasis on the intended outcome. The research was approved by the El-Nour Eye Hospital institutional review board.

Inclusion criteria were myopia of more than 12 diopters, myopia of less than 12 diopters if the patients were unsuitable for LASIK due to topography or pachymetry results according to guidelines suggested in literature, and age younger than 45 years (to obtain some accommodative potential). Exclusion criteria were intraocular pressure (IOP) outside the statistically normal range (more than $21 \mathrm{mmHg}$ ), presence of iris transillumination defects, or retinal pathology.

After appropriate counseling and signing of informed consent, the personal treatment preferences of the patients were taken into account with regard to their assignment to either group. Group 1 underwent CLE and Group 2 underwent ICL.
CLE was preferred if there was a recent increase in myopia by more than 1.0 diopter, an anterior chamber depth (ACD) less than $2.8 \mathrm{~mm}$, or if the patient was unable to afford ICL. ICL was undertaken in patients motivated to maintain their residual accommodation provided their refraction was stable, the anterior chamber was more than $2.8 \mathrm{~mm}$ deep, and adequate financial resources were available.

The preoperative evaluation included manifest and cycloplegic refraction, uncorrected (UCVA) and best-corrected visual acuity (BCVA) measured on a visual chart and expressed as Snellen's decimal, intraocular pressure (IOP) measurement by Goldmann applanation tonometry, through slit lamp biomicroscopy of the anterior segment, and dilated fundus examination using both a 90 diopters (D) lens for the posterior pole and a three-mirror lens for detailed examination of the retinal periphery.

Preoperative specular microscopy using the noncontact specular microscope (NONCON ROBO-P, Konan Medical, Torrance, CA) was done and repeated six months postoperatively. ACD, horizontal white to white diameter and corneal topography were measured using anterior segment scheimpflug imaging by Pentacam HR (OCULUS Optikgeräte $\mathrm{GmbH}$, Germany). ICL diameter, power, and optic size calculation were performed by STAAR Surgical Inc. (Monrovia, CA), using a modified vertex formula based on the above diameters with targeted postoperative emmetropia and adequate lens vaulting.

\section{Surgical technique}

All CLE procedures were performed by $\mathrm{AE}$ and $\mathrm{MH}$ who are experienced anterior segment surgeons, while all ICL procedures were performed by $\mathrm{HY}$ who had performed numerous ICL implantations prior to commencement of the study.

\section{Clear lens extraction}

All surgeries were performed under local peribulbar anesthesia through a $3.2 \mathrm{~mm}$ incision placed along the steeper meridian and the creation of two side ports. Because of the soft nucleus, often only irrigation/aspiration was used. A foldable hydrophobic acrylic IOL (SENSAR Acrylic IOL with OptiEdge, Abbott Medical Optics, Inc., Abbott Park, IL) was introduced through an injector without widening the wound, into the capsular bag, with meticulous polishing of the anterior lens capsule.

\section{Implantable collamer lens}

All surgeries were performed under local peribulbar anesthesia through a $3.2 \mathrm{~mm}$ incision placed along the steeper meridian and the creation of a single side port. The 
anterior chamber was filled with an ophthalmic viscosurgical device (OVD). Careful loading of the ICL into the cartridge was undertaken using special microforceps and with partial lubrication using a mixture of saline and OVD to eliminate electrostatic forces. The lens was then slowly injected into the anterior chamber using the STAAR injector (STAAR Surgical Inc) anterior to the iris plane, and allowed to unfold. The positioning holes on the distal and proximal footplates of the lens were checked to ensure proper orientation. The lens was rotated to be in the horizontal anterior chamber position. Each corner of the footplate was tucked beneath the iris carefully with a modified lens spatula, taking special care not to touch the optic or the crystalline lens. Once the lens was placed, the OVD was removed by irrigation/aspiration, taking care not to leave any residue. The pupil was pharmacologically constricted and a peripheral iridectomy performed at 12 o'clock using a vitrectomy probe. The wound was secured by stromal hydration.

\section{Postoperative care}

Topical antibiotic (gatifloxacin $0.3 \%$ three times a day) and steroids (prednisolone 1\% five times a day) were administered and gradually tapered over a period of four weeks. The ICL group also received oral acetazolamide $250 \mathrm{mg}$ twice daily during the first 24 hours.

\section{Outcome parameters}

The mean follow-up period was $17.1 \pm 8.56$ months. During this period the patients were examined on the first postoperative day, and at one week, two weeks, one month, and quarterly thereafter until the end of follow-up. During this period the assessed outcome parameters included last visit UCVA, refraction and BCVA, IOP (with the measurement taken at six months being representative of the postoperative reading), noncontact specular microscopy at six months, Pentacam evaluation of ACD, other postoperative complications, and the need for a secondary procedure. The ICL group additionally had slit lamp examination for inflammation and lens opacities.

\section{Statistical analysis}

Data were described using the arithmetic mean \pm SD or number and percentage when appropriate. Comparison of variables was done using the Mann-Whitney $U$ test and Wilcoxon singlerank test for between-group comparisons and comparisons within the same group, respectively. All tests were two-tailed, and a $P$ value $<0.05$ was considered statistically significant. All statistical calculations were done using the SPSS (version 10.0; SPSS Inc., Chicago, IL) statistical program.

\section{Results}

\section{Patient population}

Group 1 involved 28 eyes in 16 patients, with 12 patients being operated bilaterally and four patients unilaterally, and a mean age of $36.04 \pm 3.95$. Group 2 involved 27 eyes in 15 patients, with three patients being operated unilaterally, and a mean age of $29.26 \pm 6.82$ (see Table 1). The age was significantly different $(P=0.000)$ between the groups, but this can be explained by the inclusion criteria. Group 1 involved eight male and eight female patients, while Group 2 involved six male and nine female patients.

\section{Predictability}

The mean preoperative spherical equivalent (SEQ) was $-17.54 \pm 4.99 \mathrm{D}$ in the CLE group and $-16.45 \pm 2.64$ $\mathrm{D}$ in the ICL group. The difference was statistically

Table I Summary of patient data

\begin{tabular}{|c|c|c|c|c|c|c|c|c|c|}
\hline & \multicolumn{4}{|l|}{ CLE } & \multicolumn{4}{|l|}{ ICL } & \multirow[t]{2}{*}{ Sig } \\
\hline & Min & Max & Mean & SD & Min & $\operatorname{Max}$ & Mean & SD & \\
\hline Age & 29 & 42 & 36.04 & 3.95 & 20 & 40 & 29.26 & 6.82 & 0.000 \\
\hline Pre-UCVA & 0.02 & 0.08 & 0.041 & 0.018 & 0.02 & 0.16 & 0.36 & 0.027 & 0.072 \\
\hline Post-UCVA & 0.10 & 0.70 & 0.43 & 0.16 & 0.20 & 0.70 & 0.44 & 0.16 & 0.662 \\
\hline Pre-BCVA & 0.20 & 0.60 & 0.39 & 0.097 & 0.30 & 0.70 & 0.51 & 0.087 & 0.000 \\
\hline Post-BCVA & 0.10 & 0.90 & 0.61 & 0.18 & 0.30 & 1.00 & 0.79 & 0.16 & 0.000 \\
\hline Pre-ECD & 2784 & 3876 & 3258.54 & 295.29 & 2784 & 3332 & 3070 & 152.35 & 0.005 \\
\hline Post-ECD & 2623 & 3781 & 3112.79 & 304.13 & 2634 & 3187 & 2896 & $15 \mid .75$ & 0.002 \\
\hline Pre-SEQs & -8 & -27 & -17.54 & 4.99 & -10 & -22 & -16.45 & 2.64 & 0.319 \\
\hline Post-SEQs & -2.50 & 1.00 & -0.99 & 0.88 & -2.00 & 1.25 & -0.63 & 0.86 & 0.199 \\
\hline Pre-IOP & 10 & 22 & 16.25 & 3.34 & II & 22 & 16.15 & 3.21 & 0.909 \\
\hline Post-IOP & 9 & 25 & $|4.2|$ & 3.75 & 13 & 24 & 18.59 & 2.74 & 0.000 \\
\hline
\end{tabular}

Abbreviations: BCVA, best-corrected visual acuity; CLE, clear lens extraction; ECD, endothelial cell density; ICL, implantable collamer lens; IOP, intraocular pressure; SEQ, spherical equivalent; Max, maximum; Min, minimum; SD, standard deviation; Sig, significant; UBVA, uncorrected best visual acuity. 
insignificant $(P=0.32)$. The mean postoperative SEQs were $-0.99 \pm 0.88 \mathrm{D}$ in the CLE group and $-0.63 \pm 0.86$ $\mathrm{D}$ in the ICL group. The difference was statistically insignificant $(P=0.199)$.

The refractive results were compared with the desired postoperative refraction. In the CLE group the aim was residual myopia of $-1.00 \mathrm{D} ; 82 \%$ (23 patients) were within $\pm 1.00 \mathrm{D}$ of the desired refraction, and $100 \%$ were within \pm 2.00 D. In the ICL group the aim was emmetropia; $77 \%$ (20 patients) were within $\pm 1.00 \mathrm{D}$ of the desired refraction, and $100 \%$ were within $\pm 2.00 \mathrm{D}$. The investigators aimed for emmetropia in the ICL group because these patients retained some residual accommodative potential, but aimed for a myopia of -1.00 in the CLE group because patients who are previously myopes are seldom happy if they become emmetropic with loss of accommodation.

\section{Visual outcome}

The mean preoperative BCVA was $0.39 \pm 0.097$ in the CLE group and $0.51 \pm 0.87$ in the ICL group. The difference was statistically significant $(P=0.000)$. The mean postoperative BCVA was $0.61 \pm 0.18$ in the CLE group and $0.79 \pm 0.16$ in the ICL group. The difference was statistically significant $(P=0.000)$. However, comparisons within each group revealed a different aspect. In the CLE group, 20 patients (71.4\%) achieved a postoperative UCVA better than their preoperative BCVA, while only $14(51.8 \%)$ patients achieved this in the ICL group. In the CLE group, 15 patients (53.5\%) achieved a postoperative UCVA $\geq 0.5$ versus 12 patients $(44.4 \%)$ in the ICL group.

\section{Anatomic outcome}

In the CLE group, the mean IOP showed a reduction from a preoperative value of $16.25 \pm 3.34 \mathrm{mmHg}$ to a postoperative value of $14.21 \pm 3.75 \mathrm{mmHg}$. This shift was significant $(P<0.001)$. On the other hand, the ICL group showed an elevation of mean IOP from a preoperative value of $16.15 \pm 3.21 \mathrm{mmHg}$ to a postoperative value of $18.59 \pm 2.74 \mathrm{mmHg}$. This shift was again significant $(P<0.001)$.

Corneal endothelial cell density (ECD) showed a difference between the preoperative and postoperative values of $4.47 \%$ in the CLE group and $5.67 \%$ in the ICL group. ACD was evaluated only in the ICL group, this evaluation being performed at six months. The mean preoperative ACD of $3.18 \pm 0.14 \mathrm{~mm}$ (range 2.99-3.42) was significantly reduced to $2.99 \pm 0.17 \mathrm{~mm}$ (range $2.75-3.3$ ). The $P$ value for this variable was $<0.001$.

\section{Complications}

None of the cases in either series had significant corneal haze or edema, retinal detachment, endophthalmitis, or persistent inflammation during the follow-up period.

There were no notable complications in the CLE group, apart from the occurrence of posterior capsule opacification and the need for neodymium-doped yttrium aluminum garnet (Nd:YAG) capsulotomy. This occurred in four eyes $(14.3 \%)$.

A number of complications were noted in the ICL group. Three forms of lens opacity were evaluated postoperatively, ie, anterior subcapsular opacity, nuclear opacity, and posterior subcapsular opacity. Evaluation was done under the slit lamp after pupillary dilation. Lens opacity was considered to be significant if it caused a loss of $>$ two lines of BCVA. Overall lens opacity was noted in three eyes (11.11\%). Only one eye had significant lens opacity, with both anterior subcapsular and nuclear opacity related to a secondary glaucoma procedure and required cataract extraction (see Table 2). Lens opacity was analyzed regarding age, gender, degree of myopia, and adequate ICL vaulting. Lens opacity was not significantly related to age and gender, but significantly related to the degree of myopia (all had myopia $>18 \mathrm{D})$

Significant pigment dispersion occurred in one eye $(3.7 \%)$, with a rise of IOP $(>21 \mathrm{mmHg})$. Ultrasonic biomicroscopy examination revealed ICL iris contact at the superior-temporal quadrant, requiring a second procedure in the form of lens rotation to exact horizontal meridian which achieved marked improvement.

One eye developed pupillary block glaucoma in the early postoperative period with evident pigment blocking the iridotomy, requiring glaucoma surgery and with a rapidly progressing cataract that eventually required ICL removal, cataract extraction with placement of low power monofocal posterior chamber IOL, and with a final UCVA better than the preoperative BCVA for distance work.

One eye $(3.7 \%)$ had a macular dot hemorrhage with a drop of BCVA > two lines, with no fluorescein angiographic evidence of choroidal neovascular membrane, and with spontaneous clearance and improvement of visual acuity to one line less the preoperative BCVA.

Table 2 Incidence of postoperative lens opacity

\begin{tabular}{lll}
\hline & Clinically insignificant & Clinically significant \\
\hline Anterior subcapsular & $\mathrm{I}(3.7 \%)$ & $\mathrm{I}(3.7 \%)$ \\
Nuclear opacity & 0 & $\mathrm{I}(3.7 \%)$ \\
Posterior subcapsular & $\mathrm{I}(3.7 \%)$ & 0 \\
\hline
\end{tabular}




\section{Discussion}

In this series we tried to compare CLE and ICL for predictability, and visual and anatomic outcome for the treatment of high myopia. Both procedures showed a high predictability, with a higher percentage of cases achieving the target refraction in the CLE group than in the ICL group, although the difference was marginal ( $82 \%$ versus $77 \%)$.

The mean postoperative BCVA was $0.61 \pm 0.18$ in the CLE group and $0.79 \pm 0.16$ in the ICL group. The difference was statistically significant $(P=0.000)$. We attributed this to the higher range of error in the CLE group (highest error was $-27 \mathrm{D}$ versus $22 \mathrm{D}$ ) and consequently the retinal condition was correspondingly weaker.

The first anatomic outcome to consider is the IOP. In the CLE group, the mean IOP showed a reduction from a preoperative value of $16.25 \pm 3.34 \mathrm{mmHg}$ to a postoperative value of $14.21 \pm 3.75 \mathrm{mmHg}$. This shift was significant $(P<0.001)$. Several studies have documented a change in IOP and ACD after cataract extraction. ${ }^{40-44}$ Increases and decreases in IOP often occur postoperatively. There are several explanations for the reduction in IOP after phacoemulsification and IOL implantation. One reason is decreased resistance to aqueous humor outflow caused by an increase in ACD, although other mechanisms are also responsible for aqueous humor outflow. Postoperative release of endogenous prostaglandin $\mathrm{F}_{2}$ after cataract extraction is reported to enhance uveoscleral outflow. Reduced IOP may also be associated with hyposecretion of aqueous humor by increasing traction on the ciliary body via the ciliary zonular fibers due to postoperative fibrosis and contraction of the lens capsule. ${ }^{40}$

On the other hand, the ICL group showed an elevation of mean IOP from a preoperative value of $16.15 \pm 3.21 \mathrm{mmHg}$ to a postoperative value of $18.59 \pm 2.74 \mathrm{mmHg}$. This shift was again significant $(P<0.001)$. Reasons for this elevated IOP include forward vaulting of the ICL and consequently of the iris, highly myopic eyes being prone to developing chronic open angle glaucoma, or presence of pigment in the trabeculum. ${ }^{45}$ In our series, one eye (3.7\%) had pigment dispersion, and one eye (3.7\%) had pupillary block glaucoma in the early postoperative period, with evident pigment blocking the iridotomy, requiring glaucoma surgery with rapidly progressing cataract that eventually required ICL removal and cataract extraction with placement of a posterior chamber IOL.

The second anatomic outcome to consider is the ECD. The drop in ECD was less in the CLE than in the ICL group ( $4.47 \%$ versus $5.67 \%$, respectively). The cause of endothelial cell loss after phakic IOL implantation is multifactorial. After any surgical procedure in the anterior segment, ECD decreases in proportion to the time of surgery and the type of procedure. ${ }^{46}$ Progressive endothelial cell loss has been suggested to be the result of a chronic, smoldering uveitis associated with IOLs. Chronic subclinical inflammation has also been observed in phakic eyes with IOLs. ${ }^{47}$ It has been suggested that while endothelial cell loss continued over the first three years of follow-up ( $2 \%-3 \%$ per year), there was a cell increase of $0.1 \%$ between three years and four years, suggesting that endothelial remodeling and stability may have occurred..$^{48}$

Although multiple factors influence the side effect profile of phakic IOLs, the majority of complications can generally be predicted by the design and location of the phakic IOL within the anterior segment. The closer the phakic IOL comes to the corneal endothelium, angle structures, or crystalline lens, the greater the risk of endothelial cell loss, iris complications, and cataract, respectively. In addition to the inherent problems from phakic IOL designs, appropriate sizing of the phakic IOL, surgeon inexperience, and surgical trauma, as well as other patient-specific factors can contribute to intraoperative and postoperative complications. A comprehensive review and grouped analysis of phakic IOL complications and possible causes can be found elsewhere. ${ }^{49}$

Previous reports of posterior chamber phakic IOL surgery report an incidence of lens opacity from $1.5 \%$ to $25 \%{ }^{23,50,51}$ Some of the variation may be due to the definition of cataract or opacity and the follow-up period, as well as surgical technique. In our series, lens opacity was noted in three eyes (11.11\%). Only one eye had significant lens opacity, with both anterior subcapsular and nuclear opacity related to a secondary glaucoma procedure and cataract extraction. Several factors can play a role in the opacification of the crystalline lens, ie, surgical trauma, postoperative inflammation, use of topical steroids, and contact between the phakic IOL and the crystalline lens. Of these, one can postulate that phakic posterior chamber IOL implantation in eyes with early nuclear changes might promote the progression of these changes into the development of a clinically significant nuclear cataract. ${ }^{52}$ The thickness of the crystalline lens increases as the eye ages, and this may lead to transient or permanent contact. It can be hypothesized that implantation of phakic IOLs in patients in their 40 s or 50 s may increase the trend to develop cataracts earlier than in nonmyopic eyes. ${ }^{53}$

The increasing incidence of phakic intraocular procedures warrants education regarding management and prevention of potential complications. It may be advisable to perform 
preoperative biometry and axial length measurements on all patients undergoing phakic IOL implantation to be prepared for the future need of phacoemulsification. ${ }^{54}$

The main concern when operating on myopic eyes is retinal detachment with the attendant risk for significant visual loss. Retinal detachment secondary to cataract extraction originates from the loss and advancement of the vitreous, which is often characterized by structural modifications in myopic patients. These include massive colliquation, vitreoschisis, and fibrous organization, with consequent vitreoretinal traction. It is therefore important that the barrier provided by the capsular-zonular plane remain intact, and IOL implantation is always advisable. ${ }^{55}$ In our series of CLE, only four eyes required Nd:YAG capsulotomy, and none of the patients developed retinal detachment. We attributed this to careful preoperative screening using threemirror examination, avoiding doubtful cases, very careful polishing of the posterior capsule and the anterior leaf of the capsule to remove epithelial cells, our choice of IOL with an edge design believed to retard the occurrence of posterior capsule opacification, and a relatively short follow-up period of $17.1 \pm 8.56$ months. The incidence of this complication after CLE reported in other studies ${ }^{13,15,56}$ is variable, ranging from $0 \%$ to $8 \%$. It has been proposed that the causes of this variability are different patient characteristics and study designs. These and other previously reported studies have found associations between the risk of retinal detachment and one or more of several factors, including younger age, axial length, history of retinal detachment or surgery in the contralateral eye or lesions predisposing to retinal detachment, surgical technique and integrity of the posterior capsule, use of Nd:YAG capsulotomy, and longer follow-up time after surgery. Several papers have reported the incidence and characteristics of retinal detachment in patients with severe myopia corrected by phakic anterior chamber IOL implantation. An incidence of retinal detachment from $0.61 \%$ to $4.8 \%$ has been reported. ${ }^{17,57-60}$ No cases occurred in our series.

The choice of the procedure presents a challenge to the clinician to provide adequate informed consent. This is due to two factors, ie, the greater complexity of optical issues and the greater range of options that are available now and may be available in the future. The informed consent process involves appropriately informing patients of risks, benefits, and alternatives to the proposed procedure(s). Explaining the range of visual outcomes to patients is not for the clinician in a hurry. And neither is explaining the risks. There are obvious rare but severe risks with CLE, including retinal detachment and endophthalmitis. Equally important, however, is the discussion of quality of vision, including the possible failure to achieve adequate near vision, and the compromise associated with monovision, halos, and reduced contrast sensitivity. With ICL there is the risk of developing cataract and secondary glaucoma, so clarifying patient expectations is crucial.

Another issue that also needs to be taken into account is cost. The cost of surgery in CLE and ICL is the same, apart from the lens, which is the only different consumable. The cost of the ICL is several-fold higher than that of a highquality foldable injectable acrylic hydrophobic IOL. This is an important factor in developing countries and in some developed regions where ICL is considered to be a cosmetic procedure and therefore not funded. An additional factor to consider is the personal experience of the surgeon, because the ICL requires additional training, whereas CLE extraction is a variation of a more common procedure.

\section{Disclosures}

The authors have no financial interest in any of the products mentioned. No financial grants from public or private organization relevant to this research were received.

\section{References}

1. Javitt JC, Chiang YP. The socioeconomic aspects of laser refractive surgery. Arch Ophthalmol. 1994;112:1526-1530.

2. Rosen E, Gore C. Staar Collamer posterior chamber phakic intraocular lens to correct myopia and hyperopia. J Cataract Refract Surg. 1998;24:596-606.

3. Applegate RA, Howland HC. Magnification and visual acuity in refractive surgery. Arch Ophthalmol. 1993;111:1335-1342.

4. Baikoff G, Joly P. Comparison of minus power anterior chamber intraocular lenses and myopic epikeratoplasty in phakic eyes. Refract Corneal Surg. 1990;6:252-260.

5. Colin J, Mimouni F, Robinet A, Conrad H, Mader P. The surgical treatment of high myopia: Comparison of epikeratoplasty, keratomileusis and minus power anterior chamber lenses. Refract Corneal Surg. 1990;6:245-251.

6. Fechner PU, Strobel J, Wichmann W. Correction of myopia by implantation of a concave Worst-iris claw lens into phakic eyes. Refract Corneal Surg. 1991;7:286-298.

7. Garrana RM, Azar DT. Phakic intraocular lenses for correction of high myopia. Int Ophthalmol Clin. 1999;39:45-57.

8. Sanders DR, Vukich JA, Doney K, Gaston M. US Food and Drug Administration clinical trial of the Implantable Contact Lens for moderate to high myopia. Ophthalmology. 2003;110:255-266.

9. Perez-Santonja JJ, Bellot J, Claramonte P, Ismail MM, Alio JL. Laser in situ keratomileusis to correct high myopia. J Cataract Refract Surg. 1997;23:372-385

10. Pallikaris IG, Kymionis GD, Astyrakakis NI. Corneal ectasia induced by laser in situ keratomileusis. J Cataract Refract Surg. 2001;27:1796-1802.

11. Applegate RA, Howland HC. Refractive surgery, optical aberrations, and visual performance. J Refract Surg. 1997;13:295-299.

12. Fukala V. Surical treatment of high degrees of myopia through aphakia. Albrecht Von Graefes Arch für Ophthalmol. 1890;36:230-244.

13. Colin J, Robinet A. Clear lensectomy and implantation of low-power posterior chamber intraocular lens for the correction of high myopia. Ophthalmology. 1994;101:107-112. 
14. Goldberg MF. Clear lens extraction for axial myopia. An appraisal. Ophthalmology. 1987;94:571-582.

15. Barraquer C, Cavelier C, Mejia LF. Incidence of retinal detachment following clear-lens extraction in myopic patients. Retrospective analysis. Arch Ophthalmol. 1994;112:336-339.

16. Colin J, Robinet A, Cochener B. Retinal detachment after clear lens extraction for high myopia: Seven-year follow-up. Ophthalmology. 1999;106:2281-2284; discussion 2285.

17. Alio JL, de la Hoz F, Perez-Santonja JJ, Ruiz-Moreno JM, Quesada JA. Phakic anterior chamber lenses for the correction of myopia: A 7-year cumulative analysis of complications in 263 cases. Ophthalmology. 1999;106:458-466.

18. Baikoff G, Arne JL, Bokobza Y, et al. Angle-fixated anterior chamber phakic intraocular lens for myopia of -7 to -19 diopters. J Refract Surg. 1998;14:282-293.

19. BenEzra D, Cohen E, Karshai I. Phakic posterior chamber intraocular lens for the correction of anisometropia and treatment of amblyopia. Am J Ophthalmol. 2000;130:292-296.

20. Davidorf JM, Zaldivar R, Oscherow S. Posterior chamber phakic intraocular lens for hyperopia of +4 to +11 diopters. J Refract Surg. 1998;14:306-311.

21. Lackner B, Pieh S, Schmidinger G, et al. Outcome after treatment of ametropia with implantable contact lenses. Ophthalmology. 2003;110 2153-2161.

22. Menezo JL, Peris-Martinez C, Cisneros AL, Martinez-Costa R. Phakic intraocular lenses to correct high myopia: Adatomed, Staar, and Artisan. $J$ Cataract Refract Surg. 2004;30:33-44.

23. Pesando PM, Ghiringhello MP, Tagliavacche P. Posterior chamber collamer phakic intraocular lens for myopia and hyperopia. J Refract Surg. 1999; 15:415-423.

24. Petternel V, Koppl CM, Dejaco-Ruhswurm I, Findl O, Skorpik C, Drexler W. Effect of accommodation and pupil size on the movement of a posterior chamber lens in the phakic eye. Ophthalmology. 2004;111:325-331.

25. Pineda-Fernandez A, Jaramillo J, Vargas J, Jaramillo M, Galindez A. Phakic posterior chamber intraocular lens for high myopia. $J$ Cataract Refract Surg. 2004;30:2277-2283.

26. Zaldivar R, Davidorf JM, Oscherow S. Posterior chamber phakic intraocular lens for myopia of -8 to -19 diopters. J Refract Surg. 1998;14:294-305.

27. Alio JL. Advances in phakic intraocular lenses: Indications, efficacy, safety, and new designs. Curr Opin Ophthalmol. 2004;15:350-357.

28. Malecaze FJ, Hulin H, Bierer P, et al. A randomized paired eye comparison of two techniques for treating moderately high myopia: LASIK and artisan phakic lens. Ophthalmology. 2002;109:1622-1630.

29. Nio YK, Jansonius NM, Wijdh RH, et al. Effect of methods of myopia correction on visual acuity, contrast sensitivity, and depth of focus. $J$ Cataract Refract Surg. 2003;29:2082-2095.

30. Sarver EJ, Sanders DR, Vukich JA. Image quality in myopic eyes corrected with laser in situ keratomileusis and phakic intraocular lens. J Refract Surg. 2003;19:397-404.

31. Bylsma SS, Zalta AH, Foley E, Osher RH. Phakic posterior chamber intraocular lens pupillary block. $J$ Cataract Refract Surg. 2002;28:2222-2228.

32. Garcia-Feijoo J, Alfaro IJ, Cuina-Sardina R, Mendez-Hernandez C, Del Castillo JM, Garcia-Sanchez J. Ultrasound biomicroscopy examination of posterior chamber phakic intraocular lens position. Ophthalmology. 2003;110:163-172.

33. Gonvers $\mathrm{M}$, Bornet $\mathrm{C}$, Othenin-Girard P. Implantable contact lens for moderate to high myopia: Relationship of vaulting to cataract formation. J Cataract Refract Surg. 2003;29:918-924.

34. Gonvers M, Othenin-Girard P, Bornet C, Sickenberg M. Implantable contact lens for moderate to high myopia: Short-term follow-up of 2 models. J Cataract Refract Surg. 2001;27:380-388.

35. Jimenez-Alfaro I, Benitez del Castillo JM, Garcia-Feijoo J, Gil de Bernabe JG, Serrano de La Iglesia JM. Safety of posterior chamber phakic intraocular lenses for the correction of high myopia: Anterior segment changes after posterior chamber phakic intraocular lens implantation. Ophthalmology. 2001;108:90-99.
36. Lackner B, Pieh S, Schmidinger G, et al. Long-term results of implantation of phakic posterior chamber intraocular lenses. J Cataract Refract Surg. 2004;30:2269-2276.

37. Menezo JL, Peris-Martinez C, Cisneros-Lanuza AL, Martinez-Costa R. Rate of cataract formation in 343 highly myopic eyes after implantation of three types of phakic intraocular lenses. J Refract Surg. 2004;20:317-324

38. Sanchez-Galeana CA, Smith RJ, Sanders DR, et al. Lens opacities after posterior chamber phakic intraocular lens implantation. Ophthalmology. 2003;110:781-785.

39. Trindade F, Pereira F. Cataract formation after posterior chamber phakic intraocular lens implantation. J Cataract Refract Surg. 1998;24:1661-1663.

40. Cekic O, Batman C. Hyposecretion of aqueous: Another mechanism for reduced intraocular pressure after phacoemulsification. J Cataract Refract Surg. 1998;24:574.

41. Issa SA, Pacheco J, Mahmood U, Nolan J, Beatty S. A novel index for predicting intraocular pressure reduction following cataract surgery Br J Ophthalmol. 2005;89:543-546.

42. Pohjalainen T, Vesti E, Uusitalo RJ, Laatikainen L. Intraocular pressure after phacoemulsification and intraocular lens implantation in nonglaucomatous eyes with and without exfoliation. J Cataract Refract Surg. 2001;27:426-431.

43. Shingleton BJ, Gamell LS, O’Donoghue MW, Baylus SL, King R. Longterm changes in intraocular pressure after clear corneal phacoemulsification: Normal patients versus glaucoma suspect and glaucoma patients. J Cataract Refract Surg. 1999;25:885-890.

44. Tong JT, Miller KM. Intraocular pressure change after sutureless phacoemulsification and foldable posterior chamber lens implantation. $J$ Cataract Refract Surg. 1998;24:256-262.

45. Abela-Formanek C, Kruger AJ, Dejaco-Ruhswurm I, Pieh S, Skorpik C. Gonioscopic changes after implantation of a posterior chamber lens in phakic myopic eyes. J Cataract Refract Surg. 2001;27:1919-1925.

46. Rao GN, Aquavella JV, Goldberg SH, Berk SL. Pseudophakic bullous keratopathy. Relationship to preoperative corneal endothelial status. Ophthalmology. 1984;91:1135-1140.

47. Perez-Santonja JJ, Iradier MT, Benitez del Castillo JM, Serrano JM, Zato MA. Chronic subclinical inflammation in phakic eyes with intraocular lenses to correct myopia. J Cataract Refract Surg. 1996;22:183-187.

48. Edelhauser HF, Sanders DR, Azar R, Lamielle H. Corneal endothelial assessment after ICL implantation. J Cataract Refract Surg. 2004;30:576-583.

49. Chen LJ, Chang YJ, Kuo JC, Rajagopal R, Azar DT. Meta-analysis of cataract development after phakic intraocular lens surgery. J Cataract Refract Surg. 2008;34:1181-1200.

50. Fechner PU, Haigis W, Wichmann W. Posterior chamber myopia lenses in phakic eyes. J Cataract Refract Surg. 1996;22:178-182.

51. Menezo JL, Peris-Martinez C, Cisneros A, Martinez-Costa R. Posterior chamber phakic intraocular lenses to correct high myopia: A comparative study between Staar and Adatomed models. J Refract Surg. 2001;17:32-42.

52. Alio JL, de la Hoz F, Ruiz-Moreno JM, Salem TF. Cataract surgery in highly myopic eyes corrected by phakic anterior chamber anglesupported lenses(1). J Cataract Refract Surg. 2000;26:1303-1311.

53. Arne JL. Phakic intraocular lens implantation versus clear lens extraction in highly myopic eyes of 30 - to 50 -year-old patients. J Cataract Refract Surg. 2004;30:2092-2096.

54. Maldonado MJ, Garcia-Feijoo J, Benitez Del Castillo JM, Teutsch P. Cataractous changes due to posterior chamber flattening with a posterior chamber phakic intraocular lens secondary to the administration of pilocarpine. Ophthalmology. 2006;113:1283-1288.

55. Ravalico G, Michieli C, Vattovani O, Tognetto D. Retinal detachment after cataract extraction and refractive lens exchange in highly myopic patients. J Cataract Refract Surg. 2003;29:39-44.

56. Fritch CD. Risk of retinal detachment in myopic eyes after intraocular lens implantation: A 7 year study. J Cataract Refract Surg. 1998;24: $1357-1360$. 
57. Alio JL, Ruiz-Moreno JM, Artola A. Retinal detachment as a potential hazard in surgical correction of severe myopia with phakic anterior chamber lenses. Am J Ophthalmol. 1993;115:145-148.

58. Baikoff G. Phakic anterior chamber intraocular lenses. Int Ophthalmol Clin. 1991;31:75-86.

59. Foss AJ, Rosen PH, Cooling RJ. Retinal detachment following anterior chamber lens implantation for the correction of ultra-high myopia in phakic eyes. Br J Ophthalmol. 1993;77:212-213.
60. Ruiz-Moreno JM, Alio JL, Perez-Santonja JJ, de la Hoz F. Retinal detachment in phakic eyes with anterior chamber intraocular lenses to correct severe myopia. Am J Ophthalmol. 1999;127:270-275.

\section{Publish your work in this journal}

Clinical Ophthalmology is an international, peer-reviewed journal covering all subspecialties within ophthalmology. Key topics include: Optometry; Visual science; Pharmacology and drug therapy in eye diseases; Basic Sciences; Primary and Secondary eye care; Patient Safety and Quality of Care Improvements. This journal is indexed on

\section{Dovepress}

PubMed Central and CAS, and is the official journal of The Society of Clinical Ophthalmology (SCO). The manuscript management system is completely online and includes a very quick and fair peer-review system, which is all easy to use. Visit http://www.dovepress.com/ testimonials.php to read real quotes from published authors. 